Vol. 1, No. 1, pp. 97-105, (October 2020)

Aswan University Journal of Environmental Studies (AUJES)

Online ISSN: 2735-4237, Print ISSN: 2735-4229

Journal homepage: http://aujes.aswu.edu.eg/

E-mail: AUJES@aswu.edu.eg

Original research

\title{
Methane production from anaerobic co-digestion of primary sludge and crop residues under mesophilic condition
}

\author{
Mahmoud A. Elsayed, Ramadan Hassany*, and Mohamed F. Soliman \\ Civil Engineering Department, Faculty of Engineering, Aswan University, Egypt
}

Received: 27/8/2020

Accepted: $12 / 9 / 2020$

(C) Unit of Environmental Studies and Development, Aswan University

\begin{abstract}
:
Anaerobic digestion (AD) is one of the suitable solutions for organic waste treatment and biogas generation, so that technology has attracted international attention nowadays for its economics. This paper mainly introduces the potential of biogas production from primary sludge and crop residues. Anaerobic digestion of corchorus stalks (CS), sugarcane leaves (SL), and primary sludge (PS) were carried out, using the biochemical methane potential (BMP) tests and by using cow manure as inoculum. CS, and SL were dried at room temperature for 15 days, then they were grinded into $2-3 \mathrm{~cm}$ particles size. The BMP tests were performed using $500 \mathrm{~mL}$ digesters under mesophilic conditions. A constant ratio of 2.0 was kept between the volatile solids (VS) of inoculum and the total VS of substrates. Evaluation characterizations of used feedstock followed the APHA standard methods. The results showed that the cumulative biogas yields (CBYs) from anaerobic digestion of CS, SL and PS were 53.33, 74.67 and $50.67 \mathrm{~mL} / \mathrm{g}$ VS-added, respectively. Experimental results were approved using statistical analysis by ANOVA test at P-value less than 0.05. The results showed that SL is a highly eligible substrate for anaerobic digestion due to its high level of gas production and biodegradability.
\end{abstract}

Keywords: Anaerobic digestion, methane production, BMP test, primary sludge, crop residues.

\section{1- INTRODUCTION}

One of the most pressing issues facing many arab countries as Egypt, is the treatment of their sewage sludge (SS) and crop residues in a manner that is environmentally appropriate and not harmful to human health. This urgent problem aggravated as a result of an increase in the amount of wastewater being treated, without care in dealing with the produced sludge, as a result of that the amount of (SS) has been steadily increased (Smith, 2000). Egypt currently has 303 WWTP's that treat $11850000 \mathrm{~m}^{3} /$ day of sewage containing around 2400 tons / day of dry solids with a $0.225 \mathrm{~kg} / \mathrm{m}^{3}$ sludge production rate of treated wastewater (Ghazy et al., 2009).

Corresponding authors*: E-mail addresses: ramadanhassany@eng.aswu.edu.eg 
Also, the generation of (SS) is expected to increase significantly in the future due to the continual rapidly growing population. In traditional municipal wastewater treatment plants consisted of primary settling and follow activated sludge process, the percentage of dry solids of primary sludge (PS) around half of total percentage of the produced sludge from this plant (Turovskiy and Mathai, 2005). The disposal of sludge generated from municipal wastewater treatment plants may make higher the contemporary operating costs of the plants up to 50\% (Appels et al., 2008). Great amounts of (SS) are disposed of each year in traditional way such as land filling. Uncontrolled contamination with gas, the land scarcity and leachate emissions made land filling and incineration no longer an option in many countries (Hartmann and Ahring, 2006). It has been crucial to develop techniques for efficiently management of the generated sludge.

On the other hand, the world produces huge amounts of waste from crop residues. The amount of agricultural wastes in Egypt is estimated at approximately 35 million tons per year (Yasser et al., 2014). Agricultural wastes are primarily disposed of through burning, which can have critical environmental repercussion. Sugar cane is one of Egypt's key strategic agricultural products. It occupies second important status after wheat and mainly is grown in upper Egypt (Abdel-Maksoud, 2012). During the period of 1995-2014 the total area and average production of sugar cane were about 0.32 million feddan and 15.60 million tons (Ahmed, 2018). As well as, corchorus is an extremely popular Egyptian green vegetable. About 887 hectares is cultivated by Corchorus in Egypt and its total production is about 2173 tons (Abbas and Mousa, 2019). From the point of view of economic development and environmental protection, diverting organic wastes such as sewage sludge and crop residues to get values from them, such as energy production, is essential. (SS) contains a low level of carbon to nitrogen $(\mathrm{C} / \mathrm{N})$ ratio (Silvestre et al., 2011). Biogas production from (SS) is low and not profitable; because of (SS) has a low content of solids. The possible microbiological disturbances in anaerobic digestion of (SS) are mainly caused by the toxic effect of heavy metals and chemical compounds in (SS), so it must take in mind their effects when applying this process (Dong et al., 2013). Due to its organic nature, agro-wastes can be a valuable alternative feedstock for biogas production. The benefits of co-digesting plant materials with organic waste as sewage sludge and animal manure lie in that agro-wastes, could improve the $\mathrm{C} / \mathrm{N}$ ratio of the feedstock, thereby decreasing the risk of ammonia inhibition of digestion (Hashimoto, 1983). Added organic waste can provide buffering capacity and a wide range of nutrients (Sosnowski et al., 2003), thus potentially improving methane yields.

In recent study, Fang et al. (2011) evaluated of biogas production from the sugar production and the results showed that the optimal methane production was recorded from anaerobic digestion of sugar beet top (500 mL-CH4/gVS-added). Mokobia et al. (2012) studied experiments on anaerobic digesters to evaluate production of biogas from anaerobic digestion of sugarcane leaves (Saccharum species) at various dilution ratios at mesophilic temperature range. The result showed that dilution ratio of 1:2 was the optimum ratio. Eshore et al. (2017) enhanced biogas production from sugarcane bagasse by using selective pretreatment methods. Keerthana and Krishnaveni (2016) carried out the co-digestion of sugarcane waste in the form of sugarcane bagasse and vegetable waste to enhance the biogas production. It was concluded that the sugarcane bagasse and vegetable waste in the proportion of $50 \%$ for each feedstock, produced the higher biogas production. Elsayed et al. (2015) carried out the co-digestion of sewage sludge and wheat straw under mesophilic condition in batch reactor and the results showed that at $\mathrm{C} / \mathrm{N}$ ratio of 15, the co-digestion of (SS) and Wheat Straw generated the highest methane yield. Wu et al.(2010) indicated that a significant increase of the volumetric biogas production can be 
achieved by adding carbon rich agricultural residues, such as corn stalks, oat straw, and wheat straw to the co-digestion process with organic wastes .Kim et al.(2012) studied the co-digestion of rice straw and sewage sludge in batch digester and the results showed that high biogas production was achieved by adding the rice straw to sewage sludge. Zhang et al. (2013) reported that the combination of goat manure with corn stalks or rice straw significantly improved biogas production at all carbon-to-nitrogen $(\mathrm{C} / \mathrm{N})$ ratios. Anaerobic digestion of sugarcane leaves $(\mathrm{SL})$, corchorus stalks (CS) and primary sludge (PS) were poorly documented in the previous studies.

The aim of this study is to expand the knowledge about anaerobic digestion of sugarcane leaves (SL), corchorus stalks (CS) and primary sludge (PS) to enhance the biogas and methane production.

\section{Methodology}

\subsection{Preparation of the substrates}

The primary sludge (PS) substrate was obtained from primary sedimentation tank of the Kima wastewater treatment plant, Aswan, Egypt. The treatment system of this plant follows the activated sludge system. Corchorus stalks (CS), and sugarcane leaves (SL) were collected from a local farming area at Keft, Qena, Egypt. CS and SL were dried at room temperature. Then, the size of the substrates was reduced by using house grinder and brought up to a size of less than 3.0 $\mathrm{mm}$.

\subsection{Inoculum}

Samples of fresh cow manure were collected from a small farm located in Keft, Qena, Egypt to be used as an inoculum in the anaerobic digestion processes. To remove the dissolved methane and residual organic matter contained in the fresh manure, it was stored in an anaerobic headspace for more than one month. The measured value of Total Solids (TS) of the inoculum was found to be $9.68 \%$ relative to its dry weight while its VS amounted to $80.79 \%$ of its TS. The inoculum had a $\mathrm{pH}$ value of 4.4. In addition, total carbon (TC) and total nitrogen (TN) were measured to be $53.36 \%, 1.74 \%$ respectively.

\subsection{Analytical measurement techniques}

Total solids (TS), volatile solids (VS), and $\mathrm{pH}$ were determined according to the APHA Standard Methods (APHA, 1999). Total nitrogen (TN), total carbon (TC) were estimated by Kjeldahl method. Water displacement is the method followed to daily measure the production of biogas.

\subsection{Batch test}

Batch tests were conducted at $35^{\circ} \mathrm{C} \pm 2{ }^{\circ} \mathrm{C}$ using the method described by (Elsayed et al., 2016). Each configuration was duplicated in order to carry out a statistical analysis. $500 \mathrm{~mL}$ batch reactors with a working volume of $400 \mathrm{~mL}$ were used. The BMP test set-up is shown in Fig. 1. The temperature of all reactors was controlled using water bath. All reactors were shaked daily for one minute (Zhang et al., 2014). Before starting the experiments, $\mathrm{pH}$ value in all reactors was adjusted to be $7 \pm 0.1$ by adding $6 \mathrm{M}$ sodium hydroxide $(\mathrm{NaOH})$. The headspace of each reactor was flushed with nitrogen gas $\left(\mathrm{N}_{2}\right)$ for three minutes to be sure that the experiments under anaerobic condition. Each reactor was sealed with a poly-vinyl chloride cap that was provided with two accesses; one tube was connected to glass tubes, while the other was plugged with a plastic tubing clamp. Schematic diagram of BMP tests set-up was illustrated in Fig. 2. At the end 
of each experiment, the digestion residue of each reactor was sampled for measuring TS, and VS. The VS removal was calculated using the following equation:

$$
\mathrm{VS}_{\text {removal }}(\%)=\frac{V S_{\text {Inlet }}-V S_{\text {Outlet }}}{V S_{\text {Inlet }}} * 100
$$

Where VS removal is the volatile solids removal for the feedstock used, VS inlet is the input volatile solids for the feedstock used in $\mathrm{g} / \mathrm{L}$, and VS outlet is the exit volatile solids for the feedstock used in $\mathrm{g} / \mathrm{L}$.

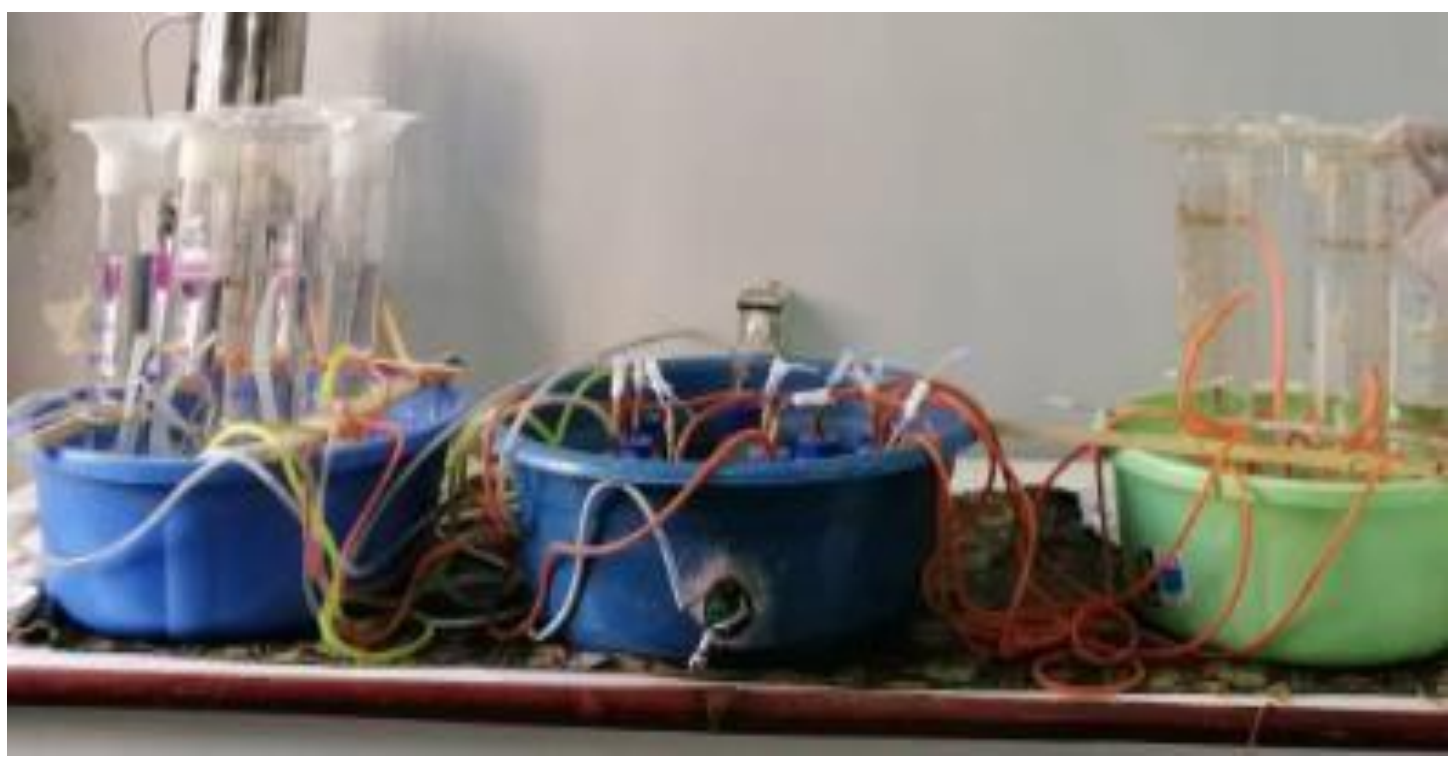

Fig1. BMP test set up.
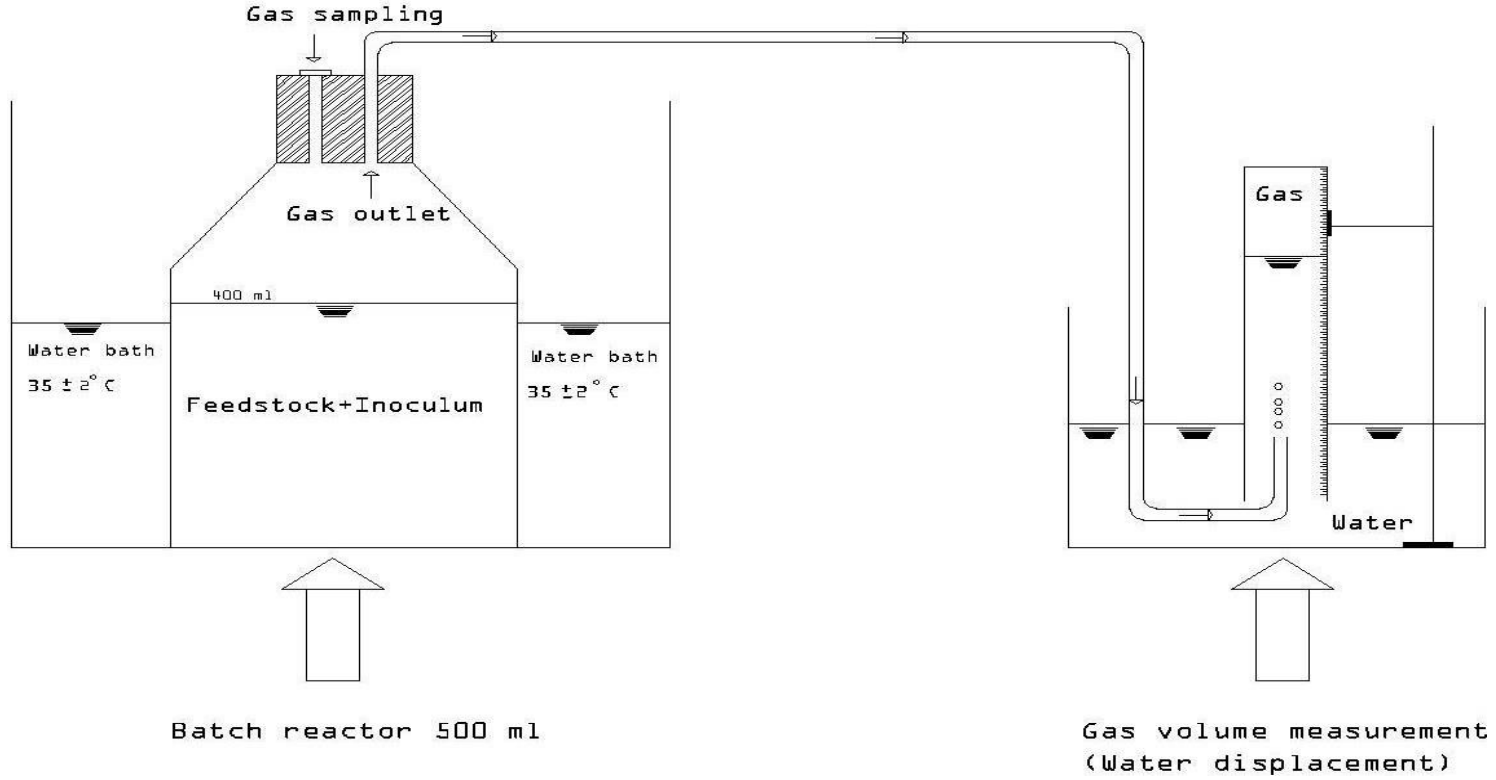

Fig 2. Schematic diagram of the biochemical methane potential (BMP) tests set-up. 


\section{RESULTS AND DISCUSSION}

\subsection{Characterization of feedstock components}

In anaerobic digestion processes, it is important to characterize the feedstock components to ensure its balance in terms of volatile solids (VS), total solids (TS), total carbon (TC), and total nitrogen (TN) contents. Feedstocks characteristics utilized in biochemical methane potential (BMP) tests were indicated in table 1. Corchorus stalks (CS), and sugar leaves (SL) were rich in carbon content with ratios of $52.94 \%$ and $52.88 \%$, respectively, relative to their dry weights, while it had low nitrogen content of $0.91 \%$, and $0.887 \%$ respectively.

In contrast primary sludge was characterized by high nitrogen content with percentages of $6 \%$ (on dry basis) and low carbon content of $45.72 \%$.

Table1: Characteristics of the feedstock components used in the BMP tests.

\begin{tabular}{c|cccc}
\hline Characteristics & TS (\%) & VS (TS\%) & TC (dry wt.\%) & TN (dry wt.\%) \\
\hline (CS) & 96.71 & 86.61 & 52.94 & 0.91 \\
\hline (SL) & 96.97 & 89 & 52.88 & 0.887 \\
$($ PS) & 4.98 & 71.13 & 45.72 & 6
\end{tabular}

Notes: $\mathrm{TS}=$ total solids, $\mathrm{VS}=$ volatile solids, $\mathrm{TC}=$ total carbon, $\mathrm{TN}=$ total nitrogen, $\mathrm{CS}=$ Corchorus stalks, $\mathrm{SL}=$ sugarcane leaves and $\mathrm{PS}=$ primary sludge.

\subsection{Biogas production from co-digestion of CS, SL and PS}

Daily biogas production from anaerobic digestion of CS, SL and PS are presented in Fig. 3. For $\mathrm{CS}$, the maximum peaks of the daily biogas yield were occurred in second day $(12.67 \mathrm{~mL} / \mathrm{g}$ VSadded) and in first day $(5.33 \mathrm{~mL} / \mathrm{g}$ VS-added). For SL, the maximum peaks of the daily biogas yield were occurred on day 1 (9.6 mL/g VS- added) and on day 4 (7.33 mL/g VS-added). For PS, the maximum peaks of the daily biogas yield were occurred on day $1(6.93 \mathrm{~mL} / \mathrm{g} \mathrm{VS}$-added) and on day 3 (5.86 mL/g VS-added). For all the wastes the plurality of methane production eventuated within the first days of the test. The two maximum peaks of the daily biogas yield of CS and SL are higher than the maximum peak of the PS, this may be due to the small particle size of the CS and SL, which is very easy for micro-organisms to digestate it. It was noted that the daily volume of the produced biogas of PS, SL, and CS decreased until there was no production in the biodigesters. This is expected since rate of reaction generally decreases with time due to decrease in concentration of active substrates. The results from our study indicate that the PS that has been used is poorly anaerobically digestible.

The cumulative biogas yields (CBYs) from anaerobic co-digestions of CS, SL and PS through continuous 30 days of experiments under mesophilic conditions are presented in Fig. 4. From this figure, it can be noted that the CBY from the single digestion of primary sludge has a lower biogas yield than the single digestion of CS and SL. the CBY obtained from SL (74.67 mL /g VS-added) was about 1.44 times higher than that from PS $(53.33 \mathrm{~mL} / \mathrm{g}$ VS-added) and about 1.51 times higher than that from PS $(50.67 \mathrm{~mL} / \mathrm{g} \mathrm{VS}$-added). 


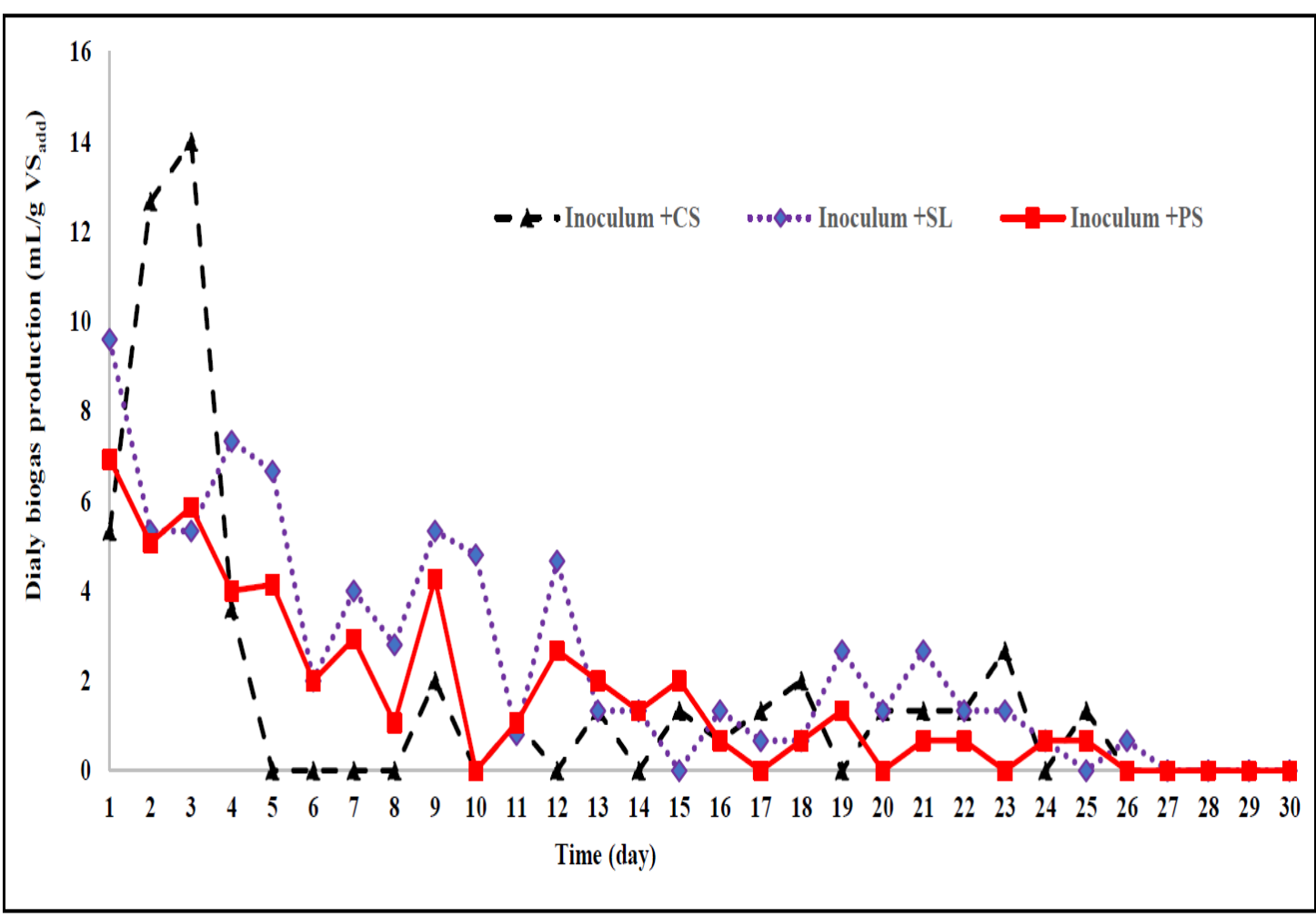

Fig 3. Daily biogas yields from anaerobic digestion of CS, SL and PS.

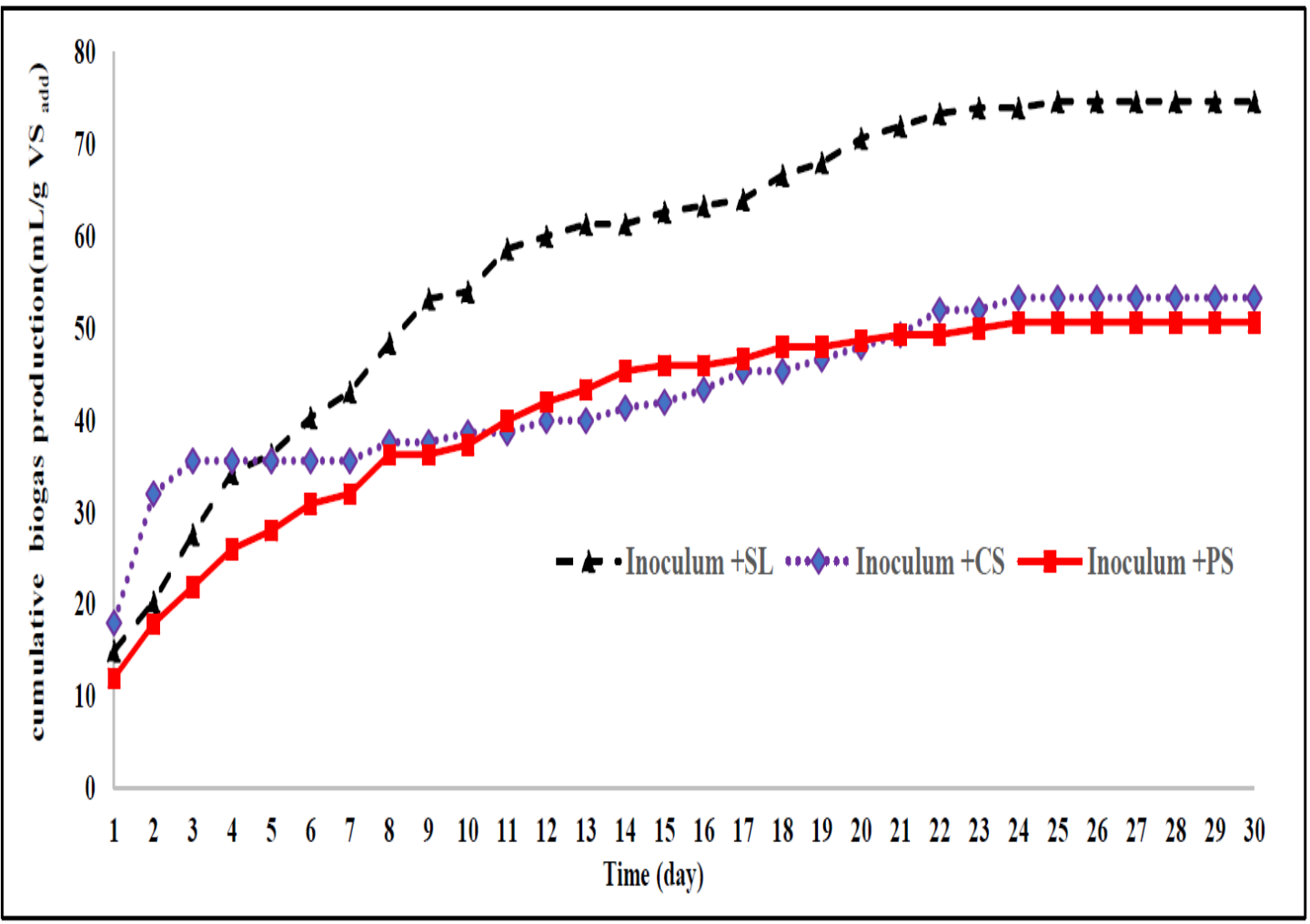

Fig 4. cumulative biogas production yields from anaerobic digestion of CS, SL and PS. 
Produced biogas from SL (74.67 mL /g VS-added) is higher than the individual digestion of PL and CS. While Inyang et al., (2010) studied anaerobic digestion of sugarcane bagasse to achieve a total of $84.74 .67 \mathrm{~mL} / \mathrm{g}$ VS-added of methane after 40 days. The findings of this study appear that the primary sewage sludge at Aswan WWTP is badly anaerobically digestible so it is essential to make a co-digestion process with other agricultural wastes.

\section{CONCLUSION}

This study investigated the possibilities of biogas production from anaerobic digestion of corchorus stalks (CS), sugarcane leaves (SL), and primary sludge (PS) by using the biochemical methane potential (BMP) tests under mesophilic conditions. A constant ratio of 2.0 was kept between the volatile solids (VS) of inoculum and the total VS of substrates. Anaerobic digestion of CS, SL, and PS increases both daily and cumulative methane yields. CBYs from anaerobic digestion of CS, SL and PS were 53.33, 74.67 and $50.67 \mathrm{~mL} / \mathrm{g}$ VS-added, respectively. The highest biogas production obtained from anaerobic digestion of SL and this may be due to its high level of biodegradability.

\section{FUTURE SCOPE}

The effect of carbon to nitrogen $(\mathrm{C} / \mathrm{N})$ ratio on anaerobic co-digestion process of primary sludge, sugar leaves and corchorus stalks in batch reactors is considered a future scope that further research in this area can be extended also study the effect of organic loading rate in semicontinuous reactor.

\section{ACKNOWLEDGMENTS}

The authors acknowledge with thanks the ministry of higher education and civil engineering department, faculty of engineering Aswan University (Egypt) funded this work.

\section{REFERENCES}

Abbas, H. S. and Mousa, A. A. (2019) 'Growth and Yield of Some Jew's Mallow (Corchorus olitorius L.) Ecotypes as Affected by Planting Dates and Foliar Application of Gibberellic and Humic Acids', Assiut Journal of Agricultural Sciences, 50(1), 107-124. doi: 10.21608/ajas.2019.33488.

Abdel-Maksoud, B. M. (2012) 'Sugarcane Production in Egypt: Synthesis of Salient Research findings', in International Conference on:"New Role for the World Sugar Economy in a Changed Political and Economic Environment". Aswan, Egypt, 10-13 November.

Ahmed, E. (2018) 'Economic Study for the Supply Response of Sugar Crops in Egypt', Arab Universities Journal of Agricultural Sciences, 26(3), 835-861. doi: 10.21608/ajs.2018.28237.

APHA (1999), 'Standard methods for the examination of water and wastewater, 'American Public Health Association/American Water Works Association /Water Environment Federation, vol. 552, 2005.

Appels, L., Baeyens, J., Degrève, J., Dewil, R. (2008) 'Principles and potential of the anaerobic digestion of waste-activated sludge', Progress in Energy and Combustion Science. 34 (6), 755-781. 
Dong, Bin Liu, Xiaoguang Dai, Lingling Dai, Xiaohu. (2013) 'Changes of heavy metal speciation during high-solid anaerobic digestion of sewage sludge', Bioresource Technology, vol. 131, pp. 152-158.

Elsayed, M., Andres, Y., Blel, W., Gad, A., (2015) 'Methane Production By Anaerobic CoDigestion Of Sewage Sludge And Wheat Straw Under Mesophilic Conditions', International Journal of Scientific \& Technology Research, 4(6), 1-6.

Elsayed, M., Andres, Y., Blel, W., Gad, A., Ahmed, A., (2016) 'Effect of VS organic loads and buckwheat husk on methane production by anaerobic co-digestion of primary sludge and wheat straw', Energy Conversion and Management. Elsevier Ltd, 117, 38-547. doi: 10.1016/j.enconman.2016.03.064.

Eshore, S., Mondal, C. and Das, A. (2017) 'Production of Biogas from Treated Sugarcane Bagasse', International Journal of Scientific Engineering and Technology, 6(7),224. doi: 10.5958/2277-1581.2017.00025.0.

Fang, C., Boe, K. and Angelidaki, I. (2011) 'Anaerobic co-digestion of by-products from sugar production with cow manure', Water Research. Elsevier Ltd, 45(11)3473-3480. doi: 10.1016/j.watres.2011.04.008.

Ghazy, M., Dockhorn, T. and Dichtl, N. (2009) 'Sewage sludge management in Egypt: Current status and perspectives towards a sustainable agricultural use', World Academy of Science, Engineering and Technology. International Journal of Environmental and Ecological Engineering ,3(9),270-278.

Hartmann, H. and Ahring, B. K. (2006) 'Strategies for the anaerobic digestion of the organic fraction of municipal solid waste: An overview', Water Science and Technology, 53(8),722. doi: 10.2166/wst.2006.231.

Hashimoto, A. G. (1983) 'Conversion of straw-manure mixtures to methane at mesophilic and thermophilic temperatures', Biotechnology and Bioengineering, vol. XXV, pp.185-200.doi: 10.1002/bit.260250115.

Inyang, M., Gao, B., Pullammanappallil, P., Ding, W., Zimmerman, A.R., (2010). 'Biochar from anaerobically digested sugarcane bagasse'. Bioresour Technol. 101(22), 8868-8872. doi: https://doi.org/10.1016/j.biortech.2010.06.088

Keerthana, T. and Krishnaveni, A. (2016) 'Biogas Production from Sugarcane Bagasse in CoDigestion with Vegetable Waste', International Journal of Latest Engineering Research and Applications, 01(03), 2455-7137.

Kim, Mijung Yang, Yingnan Morikawa-Sakura, Marino S.Wang, Qinghong Lee, Michael V. Lee, Dong Yeol Feng, Chuanping Zhou, Yulin Zhang, Zhenya (2012) 'Hydrogen production by anaerobic co-digestion of rice straw and sewage sludge', International Journal of Hydrogen Energy. 37(4), 3142-3149 doi: 10.1016/j.ijhydene.2011.10.116.

Mokobia, K., Ikhuoria, E.U., Olugbemide, D., Omorogbe, S.O., (2012) 'Production and Characterization of Biogas obtained from Sugarcane leaves Production and Characterization of Biogas obtained from Sugarcane leaves (Saccharum species)', International Journal of Basic and Applied Sciences Omorogbe et.al International Journal of Basic and Applied Sciences, 11(33), 258-262. 
Silvestre, G., Rodríguez-Abalde, A., Fernández, B., Flotats, X., Bonmatí, A., (2011) 'Biomass adaptation over anaerobic co-digestion of sewage sludge and trapped grease waste', Bioresource Technology. 102(13) 6830-6836 doi: 10.1016/j.biortech.2011.04.019.

Smith, S. R. (2000) 'MANAGEMENT, USE, AND DISPOSAL OF SEWAGE SLUDGE S: In Book " WASTE MANAGEMENT AND MINIMIZATION". Encyclopedia of Life Support Systems (EOLSS).

Sosnowski, P., Wieczorek, A. and Ledakowicz, S. (2003) 'Anaerobic co-digestion of sewage sludge and organic fraction of municipal solid wastes', Advances in Environmental Research. 7(3) 609-616 doi: 10.1016/S1093-0191(02)00049-7.

Turovskiy, I. S. and Mathai, P. K. (2005) Wastewater Sludge Processing, Wastewater Sludge Processing. John Wiley \& Sons, Hoboken, NJ, USA.

Wu, X., Yao, W., Zhu, J., Miller, C., (2010) 'Biogas and CH4 productivity by co-digesting swine manure with three crop residues as an external carbon source', Bioresource Technology. 101(11), 4042-4047. doi: 10.1016/j.biortech.2010.01.052.

Yasser S., Hatm M., Fayza (2014) 'An Economic Study of Recycling Agricultural Wastes in Egypt', Arab Universities Journal of Agricultural Sciences, 22(2), 213-222. doi: 10.21608/ajs.2014.14732.

Zhang, T., Liu, L., Song, Z., Ren, G., Feng, Y., Han, X., Yang, G., (2013) 'Biogas Production by Co-Digestion of Goat Manure with Three Crop Residues', PLoS ONE. 8(6) 1-7 doi: 10.1371/journal.pone.0066845.

Zhang, W., Wei, Q., Wu, S., Qi, D., Li, W., Zuo, Z., Dong, R., (2014) 'Batch anaerobic codigestion of pig manure with dewatered sewage sludge under mesophilic conditions', Applied Energy, 128, 175-183. doi: 10.1016/j.apenergy.2014.04.071. 